\title{
Bromide-Assisted Anisotropic Growth of Gold Nanoparticles as Substrates for Surface-Enhanced Raman Scattering
}

\author{
Melissa A. Kerr and Fei Yan \\ Department of Chemistry, North Carolina Central University, Durham, NC 27707, USA \\ Correspondence should be addressed to Fei Yan; fyan@nccu.edu
}

Received 7 August 2016; Accepted 12 October 2016

Academic Editor: Nikša Krstulović

Copyright ( 2016 M. A. Kerr and F. Yan. This is an open access article distributed under the Creative Commons Attribution License, which permits unrestricted use, distribution, and reproduction in any medium, provided the original work is properly cited.

We report herein a one-step synthesis of gold nanoparticles (Au NPs) of various shapes such as triangles, hexagons, and semispheres, using 5-hydroxyindoleacetic acid (5-HIAA) as the reducing agent in the presence of potassium bromide (KBr). Anisotropic Au NPs have received ever-increasing attention in various areas of research due to their unique physical and chemical properties. Numerous synthetic methods involving either top-down or bottom-up approaches have been developed to synthesize Au NPs with deliberately varied shapes, sizes, and configurations; however, the production of templateless, seedless, and surfactant-free singularshaped anisotropic Au NPs remains a significant challenge. The concentrations of hydrogen tetrachloroaurate $\left(\mathrm{HAuCl}_{4}\right), 5-\mathrm{HIAA}$, and $\mathrm{KBr}$, as well as the reaction temperature, were found to influence the resulting product morphology. A detailed characterization of the resulting Au NPs was performed using ultraviolet-visible (UV-Vis) spectroscopy, scanning electron microscopy (SEM), and Raman spectroscopy. The as-prepared Au NPs exhibited excellent surface-enhanced Raman scattering (SERS) properties, which make them very attractive for the development of SERS-based chemical and biological sensors.

\section{Introduction}

Raman spectroscopy, based on molecular vibrational transitions, has long been regarded as a valuable tool for the identification and quantification of chemical and biological species $[1,2]$. While it is well known that signals in normal Raman spectroscopy are extremely weak, great progress has been made since the discovery of surface-enhanced Raman scattering (SERS) [3-5]. A great deal of recent research has been delving into how effective Au NPs are as SERS substrates. The surface chemistry of gold is quite versatile, as it can easily be manipulated into a variety of sizes and shapes [6-10]. The electron cloud plasmons and the wavelength where that metal nanoparticle absorbs photons are directly affected by the type, shape, size, and structure of the metal nanoparticle. If it is possible to match the plasmon absorption wavelength of Au NPs with the excitation wavelength of the laser, resonance Raman, yet another boost to the Raman signal, is possible. Therefore, being able to manipulate the size and shape of a gold nanoparticle would allow for simple and easy modifications to analytical devices that utilize SERS technology that would greatly improve sensitivity and selectivity.

It has been shown that Au NPs can be synthesized in any number of sizes or shapes quite easily. The Au NPs that have been synthesized are nanoflowers $[1,11]$, planar triangles (or prisms) [12-14], planar hexagons [12], nanorods $[13,15,16]$, spheres $[17,18]$, octahedra, and cubes [19], to name just a few. Even though the toxicity of Au NPs has been widely studied, they have not been shown to be toxic to humans [9]. With this in mind, Au NPs can be utilized for a broad range of biomedical sensing, diagnostics, or other biomedical-based applications [12].

Herein, we report a facile approach for the synthesis of anisotropic Au NPs of various shapes such as triangles, hexagons, and semispheres, using 5-hydroxyindoleacetic acid (5-HIAA) as the reducing agent in the presence of potassium bromide $(\mathrm{KBr})$. The concentrations of hydrogen tetrachloroaurate $\left(\mathrm{HAuCl}_{4}\right), 5$ - $\mathrm{HIAA}$, and $\mathrm{KBr}$, as well as the reaction temperature, were found to influence the resulting 
product morphology. A detailed characterization of the resulting $\mathrm{Au}$ NPs was performed using ultraviolet-visible (UV-Vis) spectroscopy, scanning electron microscopy (SEM), and Raman spectroscopy. The as-prepared Au NPs exhibited excellent SERS properties, which make them very attractive for the development of SERS-based chemical and biological sensors.

\section{Materials and Methods}

2.1. Chemicals. Hydrogen tetrachloroaurate $(1 \% \mathrm{w} / \mathrm{v})$ was obtained from Ricca Chemical Company, 5-hydroxyindole3-acetic acid (5-HIAA, 99\%) and crystal violet were obtained from Acros Organics, and potassium bromide (KBr, 99\% FTIR grade) was obtained from Sigma-Aldrich. All solutions were prepared with high purity deionized water (resistivity $\geq 18 \mathrm{M} \Omega \cdot \mathrm{cm}$ ) from a Picopure ${ }^{\circledR} 2$ ultrapure water purification system (Hydro, Inc.).

2.2. Synthesis of Anisotropic Gold Nanoparticles in the Absence of $\mathrm{KBr}$. A $0.75 \mathrm{mM}$ solution of 5-HIAA was created by adding $7.17 \mathrm{mg}$ of 5 -HIAA to $50 \mathrm{~mL}$ of $\mathrm{diH}_{2} \mathrm{O}$ (DI). The solution was sonicated for about 1 minute until there was no longer any visual evidence of the solid 5-HIAA. On a stir plate, $44.42 \mathrm{~mL}$ of DI, $5 \mathrm{~mL}$ of $0.75 \mathrm{mM} 5$-HIAA, and $579.2 \mu \mathrm{L}$ of $1 \% \mathrm{HAuCl}_{4}$ were mixed at approximately $300 \mathrm{rpm}$ for 30 minutes under ambient conditions. The color turned gray about a minute after addition of the 5-HIAA. At the end of the 30-minute period, the sample started to turn to a salmon-pink color.

2.3. Synthesis of Anisotropic Gold Nanoparticles in the Presence of $\mathrm{KBr}$. A $0.75 \mathrm{mM}$ solution of 5-HIAA was created by adding $7.17 \mathrm{mg}$ of 5 -HIAA to $50 \mathrm{~mL}$ of $\mathrm{diH}_{2} \mathrm{O}$ (DI). The solution was sonicated for about 1 minute until there was no longer any visual evidence of the solid 5-HIAA. A $0.60 \mathrm{mM}$ solution of $\mathrm{KBr}$ was made by adding $3.57 \mathrm{mg}$ of $\mathrm{KBr}$ to $50 \mathrm{~mL}$ of $\mathrm{DI}$. Synthesis was performed using increasing volumes of $\mathrm{KBr}$. In a beaker, $4 \mathrm{~mL}, 5 \mathrm{~mL}$, and $6 \mathrm{~mL}$ of $0.60 \mathrm{mM} \mathrm{KBr}, 5 \mathrm{~mL}$ of $0.75 \mathrm{mM} 5$-HIAA, and $579.2 \mu \mathrm{L}$ of $\mathrm{HAuCl}_{4}(1 \% \mathrm{w} / \mathrm{v})$ were mixed with DI water in a solution of $50 \mathrm{~mL}$. The solutions were mixed on a stir plate set at approximately $300 \mathrm{rpm}$ for 30 minutes under ambient conditions. The color turned yellow about a minute after addition of the 5-HIAA and then to gray and purple after about 5 minutes.

2.4. UV-Vis Spectrophotometry. The UV-Vis spectra were obtained using an Evolution $220 \mathrm{UV}$-Vis spectrophotometer. The spectra measured absorbance from 400 to $750 \mathrm{~nm}$, with a $100 \% \mathrm{~T}$ baseline correction. Samples were analyzed in a standard quartz cuvette.

2.5. Scanning Electron Microscopy (SEM) Analysis. SEM images were obtained using a FEI XL-30 Field Emission SEM. The accelerating voltage used was $30 \mathrm{kV}$ with a spot size of 2. A working distance of around $7 \mathrm{~mm}$ was used to optimize the magnification using the through-the-lens detector (TLD). Samples were prepared on a silicon wafer.
2.6. Raman Spectroscopy. Raman spectra were acquired using a Renishaw RM1000 Raman microspectrometer (with a 20x objective). The Raman system was coupled to an Olympus $\mathrm{BH}-2$ microscope and equipped with a $785 \mathrm{~nm}$ diode laser, an edge filter with $200 \mathrm{~cm}^{-1}$ cutoff, 1200 -line/mm grating, and a thermoelectrically cooled CCD detector. The system is operated using Renishaw WIRE ${ }^{\mathrm{TM}}$ software (version 3.3).

\section{Results and Discussion}

3.1. Effect of Varied Order and Manner of Addition. In order to determine the best order and manner of addition, a series of 4 samples all began by adding $44.42 \mathrm{~mL}$ of DI on a stir plate. Sample 1 was performed by adding $5 \mathrm{~mL}$ of $0.75 \mathrm{mM} 5$-HIAA, followed by simple addition of $579.2 \mu \mathrm{L}$ of $1 \% \mathrm{HAuCl}_{4}$. Sample 2 was the same as sample 1 , but with dropwise addition of $\mathrm{HAuCl}_{4}$. Sample 3 was performed by adding $579.2 \mu \mathrm{L}$ of $1 \%$ $\mathrm{HAuCl}_{4}$, followed by dropwise addition of $5 \mathrm{~mL}$ of 5 -HIAA. Sample 4 was the same as sample 3 , but with simple addition of 5-HIAA. From the resulting SEM images seen in Figure 1, it was observed that all of the variations were successful in creating gold nanoparticles. The simple addition of $\mathrm{HAuCl}_{4}$ to the solution of 5-HIAA was the method that garnered the most gold nanoparticles.

3.2. Effect of Varied Mixing Parameters. In order to determine the optimal mixing parameters, the two conditions tested were to gently agitate synthesis solution on a platform agitator and to vigorously agitate on a stir plate set at around $300 \mathrm{rpm}$. From the resulting SEM images seen in Figure 2, it was observed that both variations were successful in creating gold nanoparticles of the same size and shape. In general, the results showed that there were more nanoparticles seen using the vigorous mixing parameter.

3.3. Effect of Reaction Temperatures. The gold nanoparticle synthesis was performed with variances in the temperature at which the synthesis was performed, either in a $15^{\circ} \mathrm{C}$ bath, at room temperature, or in a $45^{\circ} \mathrm{C}$ bath. From the resulting SEM images seen in Figure 3, it was observed that all three variations were successful in creating gold nanoparticles, but the shapes and sizes were different in each temperature set. The lower temperature set did not create as many gold nanoparticles, and there seemed to be some residual unreacted material. The heated synthesis showed more nanoparticles, but the edges and forms were less defined. The results showed that the room temperature synthesis was the most successful in creating gold nanoparticles.

3.4. Effect of Varied Concentrations of Reactants. The gold nanoparticle synthesis was performed with variances in the concentrations of both $\mathrm{HAuCl}_{4}$ and 5-HIAA. Specifically, the first concentration variation was to the $0.75 \mathrm{mM}$ of 5-HIAA. The initial volumes of DI were varied to compensate for the variations of 5-HIAA added. In samples 1 through 5, $10 \mathrm{~mL}$, $5 \mathrm{~mL}, 2.5 \mathrm{~mL}, 1.67 \mathrm{~mL}$, and $1.25 \mathrm{~mL}$ of $0.75 \mathrm{mM} 5$-HIAA were added. The volume of $1 \% \mathrm{HAuCl}_{4}$ added remained constant at $579.2 \mu \mathrm{L}$. A second set of syntheses were performed as stated 


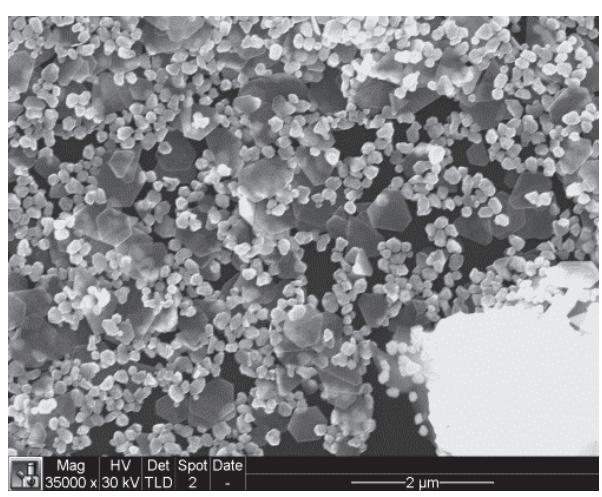

(a)

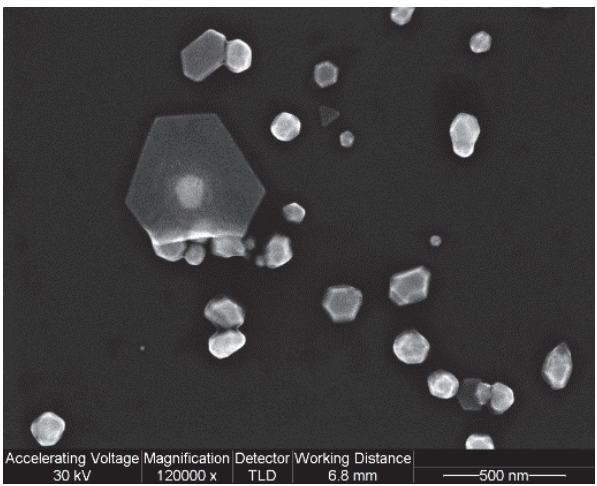

(c)

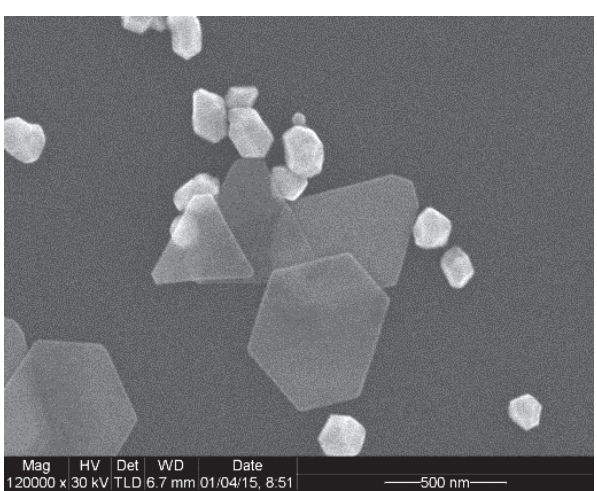

(b)

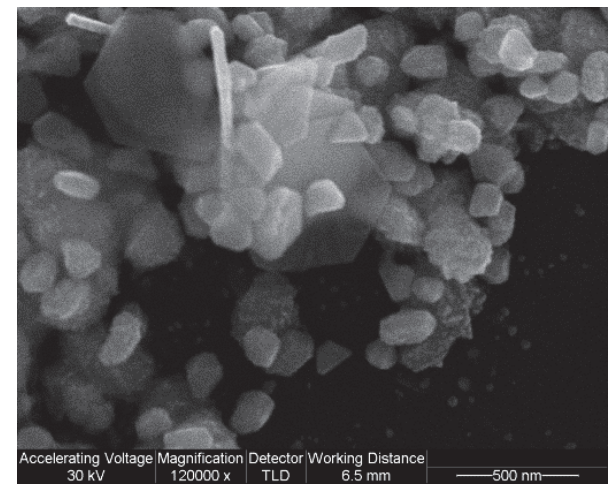

(d)

FIGURE 1: SEM images showing results from gold nanoparticle synthesis with variances in manner and order of addition. (a) Simple addition of $\mathrm{HAuCl}_{4}$ to solution of 5-HIAA. (b) Dropwise addition of $\mathrm{HAuCl}_{4}$. (c) Dropwise addition of 5-HIAA to solution of $\mathrm{HAuCl}_{4}$. (d) Simple addition of 5-HIAA to solution of $\mathrm{HAuCl}_{4}$.

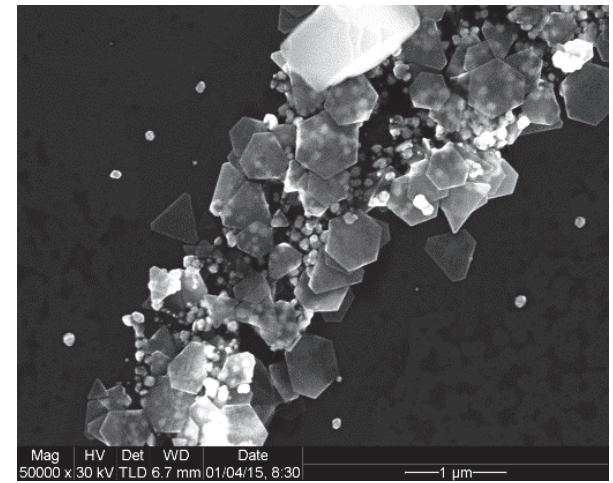

(a)

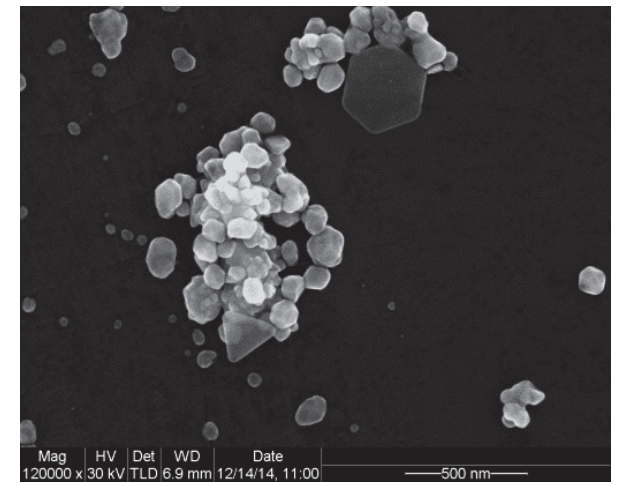

(b)

FIGURE 2: SEM images showing results from gold nanoparticle synthesis with variances in mixing parameters. (a) Vigorous mixing at around $250 \mathrm{rpm}$ and (b) gentle mixing on a platform agitator.

in Section 2.2, but with a variation in the concentrations of $\mathrm{HAuCl}_{4}$. The initial volumes of DI were varied to compensate for the variations of $\mathrm{HAuCl}_{4}$ added, while the volume of $0.75 \mathrm{mM} 5$-HIAA remained constant at $5 \mathrm{~mL}$. In samples 1 through $4,678.0 \mu \mathrm{L}, 579.2 \mu \mathrm{L}, 482.6 \mu \mathrm{L}$, and $386.1 \mu \mathrm{L}$ of $1 \% \mathrm{HAuCl}_{4}$ were added. The resulting SEM images seen in Figure 4 were from the variances in 5-HIAA. It was observed that all variations were successful in creating gold nanoparticles, but the shapes and sizes were different for each concentration of 5-HIAA.

A higher concentration seemed to hinder the reaction, where the concentration in the literature resulted in gold nanoparticles more consistent with previous results. The lower concentrations created gold nanoparticles with less 


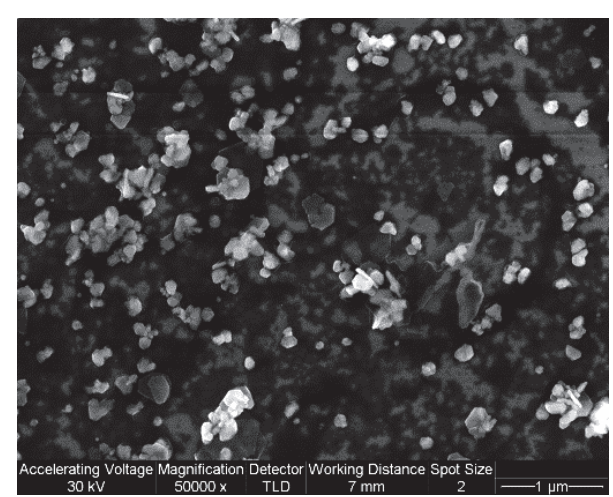

(a)

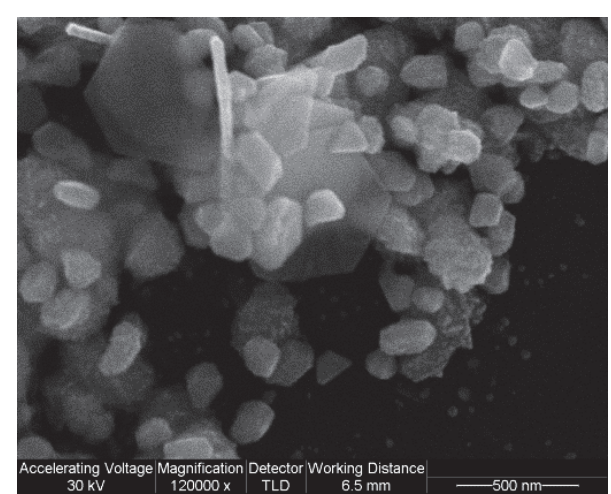

(b)

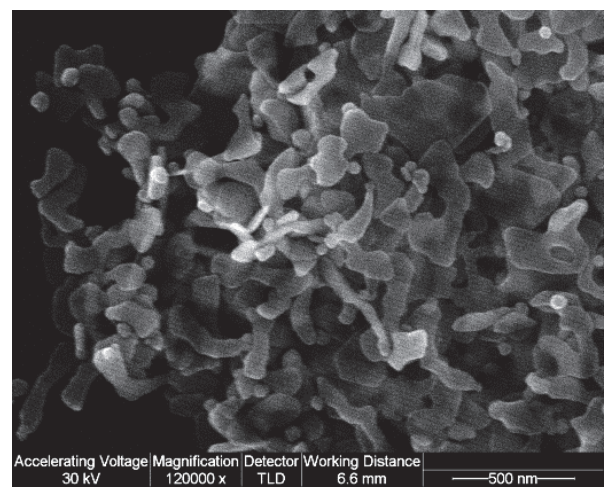

(c)

FIGURE 3: SEM images showing results from gold nanoparticle synthesis with variances in the temperature at which the synthesis was performed. (a) $15^{\circ} \mathrm{C}$ bath, (b) room temperature, and (c) $45^{\circ} \mathrm{C}$ bath.

defined edges and inconsistent shapes. The resulting SEM images seen in Figure 5 were from the variances in $\mathrm{HAuCl}_{4}$. It was observed that all variations were successful in creating gold nanoparticles of similar shapes and sizes. The concentration of the $\mathrm{HAuCl}_{4}$ did not seem to be as strong of a determining factor in the synthesis. There does seem to be a lower threshold, as the lowest concentrations still created gold nanoparticles, but with less of a population.

3.5. Effect of Potassium Bromide. Figure 6 shows the SEM images of the resulting gold nanoparticles when increasing concentrations of $\mathrm{KBr}$ were added to the synthesis. All three variations show that gold nanoparticles were successfully created. The lower concentration of $\mathrm{KBr}$ seemed to hinder the synthesis. The higher concentration of $\mathrm{KBr}$ created many planar shapes, but the edges of the nanoparticles were worn away, as seen in the inset picture of Figure 6(c). The synthesis involving the introduction of $0.075 \mathrm{mM} \mathrm{KBr}$ showed a great increase of planar shapes as compared to the synthesis in the absence of KBr. The synthesis with the addition of $0.075 \mathrm{mM}$ $\mathrm{KBr}$ seemed to lead to the intended direction of more planar shapes as compared to the original synthesis. $\mathrm{KBr}$ is, in and of itself, a reducing agent [19]. The dependence of nanoparticle morphology on bromide concentration may be explained based on the preferential adsorption of bromide on the (111) crystal facet of $\mathrm{Au}$, as it was previously shown that halide ions adsorb on gold surfaces with binding energies that scale with crystal facet $((111)>(110)>(100))[18,20]$.

3.6. Characterization and Analytical Applications of Anisotropic $A u$ NPs. Figure 7 shows two aspects of the synthesis: (1) visual images of the resulting gold nanoparticle solutions in the absence of $\mathrm{KBr}$ (left) and in the presence of $0.075 \mathrm{mM}$ $\mathrm{KBr}$ (right) and (2) their corresponding UV-Vis spectra. Typical UV-visible absorption values for this kind of gold nanoparticle synthesis are around $540 \mathrm{~nm}$ [21]. The synthesis without $\mathrm{KBr}$ was close to this value, with the $\mathrm{KBr}$-mediated synthesis nanoparticles showing absorption at wavelengths a bit longer. UV-Vis absorption spectrum could not be obtained for the as-prepared $\mathrm{Au} \mathrm{NP}$ solution with the addition of $0.090 \mathrm{mM} \mathrm{KBr}$, as all the Au NPs sank to the bottom of the cuvette.

Figure 8 shows the Raman spectra of crystal violet $(1 \mathrm{mM})$ obtained from these two syntheses with $785 \mathrm{~nm}$ excitation. Top spectrum was measured from Batch 1 Au NPs solution which contained $0.075 \mathrm{mM} \mathrm{KBr}$ and gives a much higher signal for this excitation wavelength. An estimated enhancement factor of $5.4 \times 10^{6}$ was obtained on the basis of the intensity of the band centered at $724 \mathrm{~cm}^{-1}$ in the crystal 


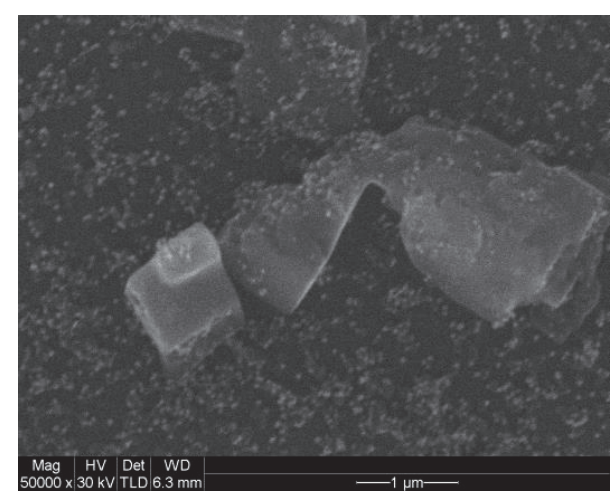

(a)

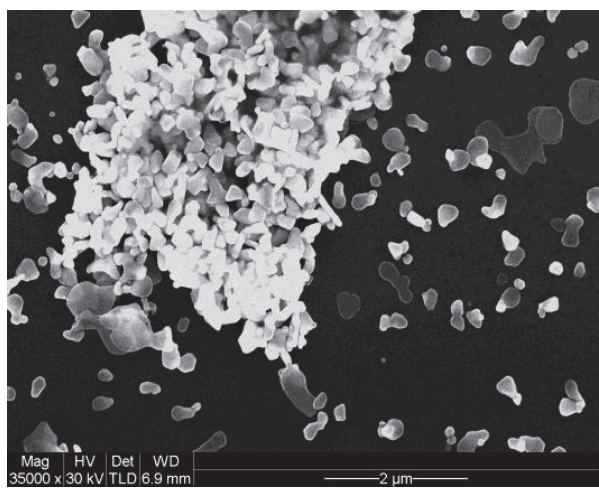

(c)

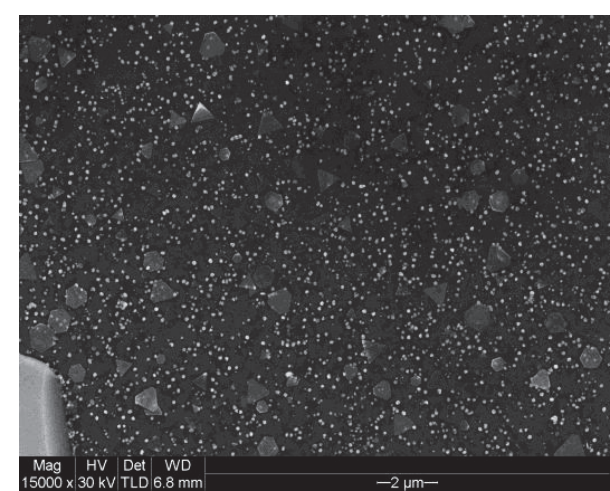

(b)

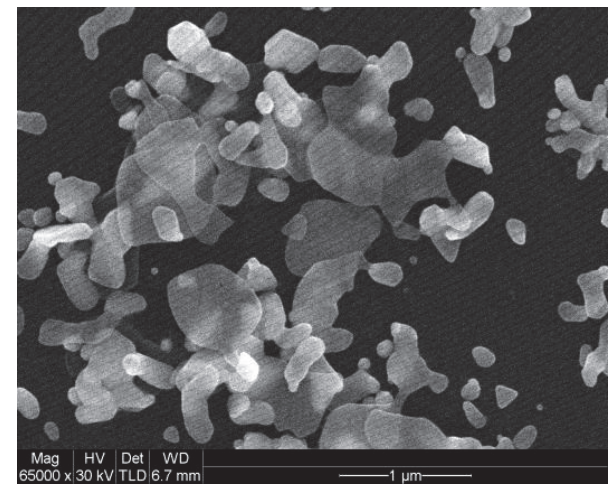

(d)

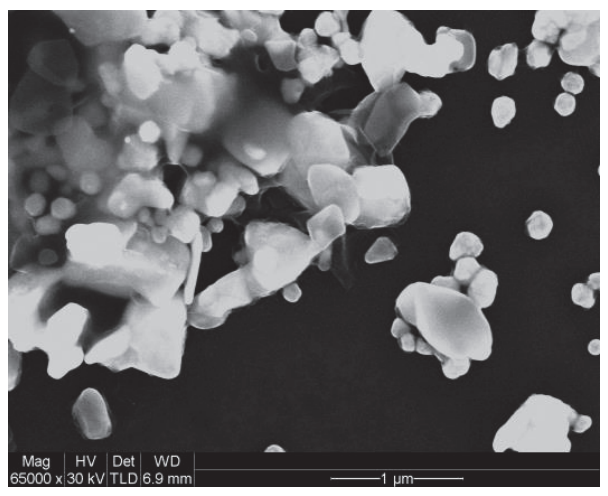

(e)

FIGURE 4: SEM images showing results from gold nanoparticle synthesis with variances in concentration of 5-HIAA. (a) 0.150 mM, (b) $0.075 \mathrm{mM}$, (c) $0.038 \mathrm{mM}$, (d) $0.025 \mathrm{mM}$, and (e) $0.019 \mathrm{mM}$.

violet Raman spectra. Postsynthesis isolation of individual shapes of gold nanoprisms via techniques such as sucrose gradient separation [21] is currently underway in our group.

\section{Conclusions}

We have demonstrated the facile synthesis of anisotropic $\mathrm{Au}$ NPs, which did not involve the use of any templates, seeds, surfactants, or polymers. Temperature, order and manner of addition, and ratio of chloroauric acid to reducing agent are extremely important. The most successful procedure which led to the production of the largest number of Au nanoprisms within a batch of nanoparticles is as follows. $5 \mathrm{~mL}$ of 5HIAA $(0.75 \mathrm{mM}), 579.2 \mu \mathrm{L}$ of $\mathrm{HAuCl}_{4}(1 \% \mathrm{w} / \mathrm{v})$, and $5 \mathrm{~mL}$ of $\mathrm{KBr}(0.75 \mathrm{mM})$ were mixed with DI water to form a solution of a total volume of $50 \mathrm{~mL}$. The solutions were mixed on a stir plate set at approximately $300 \mathrm{rpm}$ for 30 minutes under ambient conditions. The as-prepared Au NPs exhibited excellent Raman enhancement when tested with a Raman-active compound (i.e., crystal violet) and showed great potential as a novel substrate for SERS-based chemical and biological sensors. 


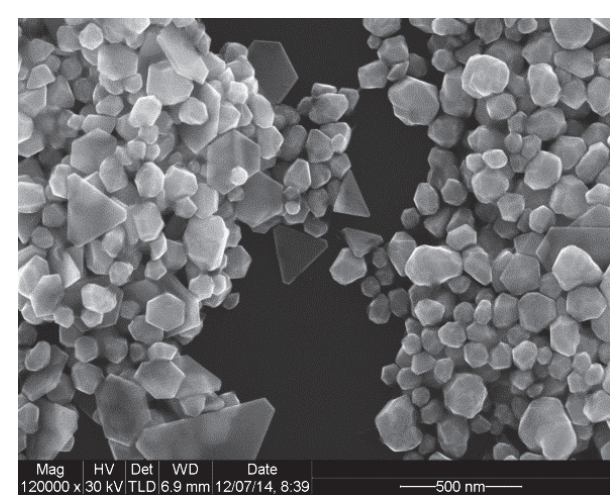

(a)

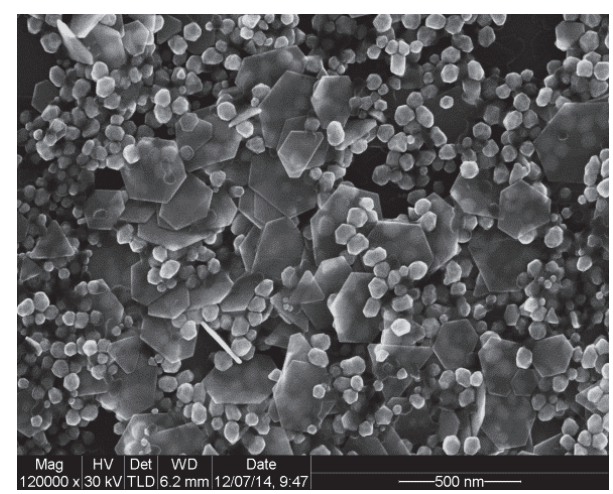

(c)

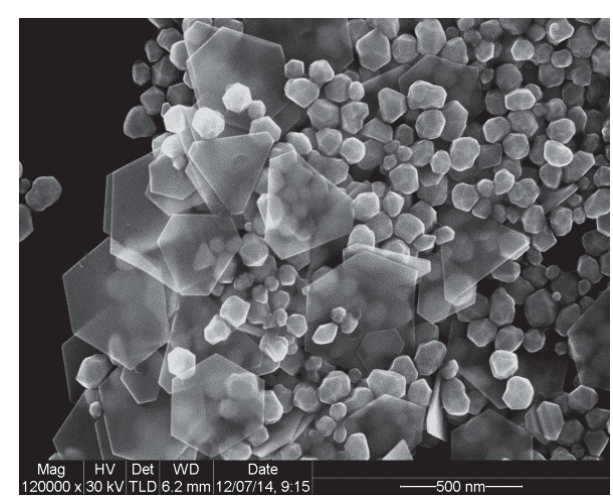

(b)

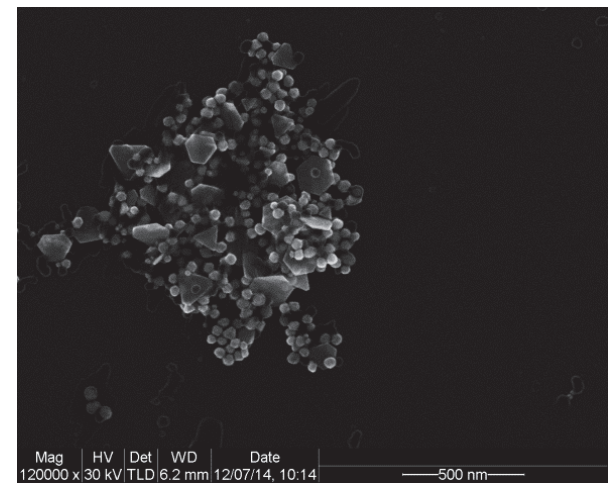

(d)

FIGURE 5: SEM images showing results from gold nanoparticle synthesis with variances in concentration of $\mathrm{HAuCl}_{4}$. (a) $0.40 \mathrm{mM}$, (b) $0.30 \mathrm{mM}$, (c) $0.25 \mathrm{mM}$, and (d) $0.20 \mathrm{mM}$.

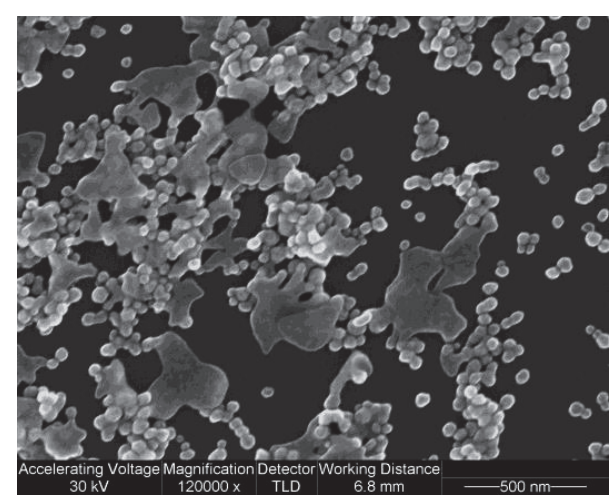

(a)

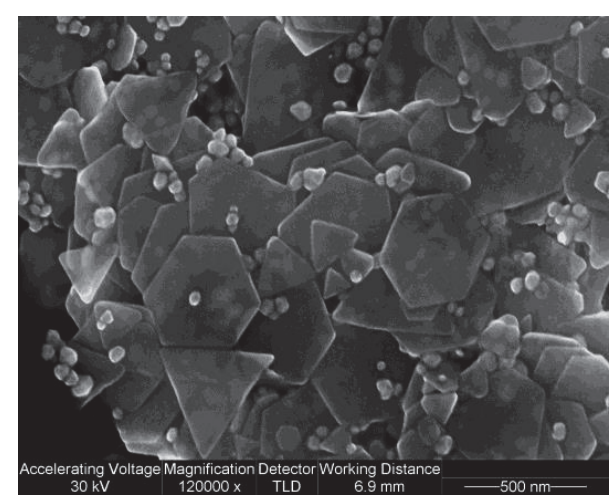

(b)

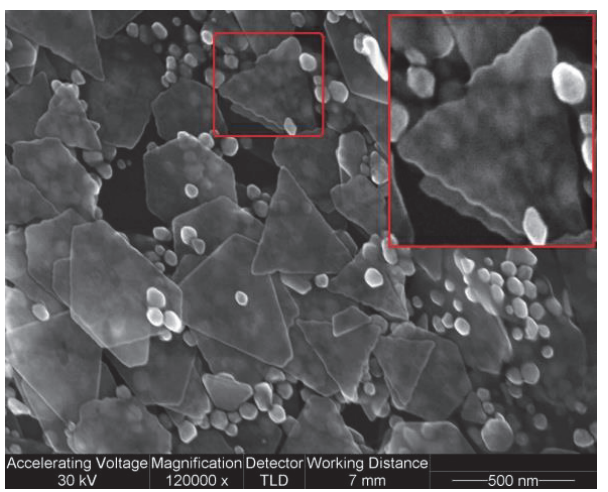

(c)

FIGURE 6: SEM images showing results from gold nanoparticle synthesis with variances in $\mathrm{KBr}$ concentrations. (a) $0.060 \mathrm{mM} \mathrm{KBr}$, (b) $0.075 \mathrm{mM} \mathrm{KBr}$, and (c) $0.090 \mathrm{mM} \mathrm{KBr}$ with inset of zoomed-in section. 


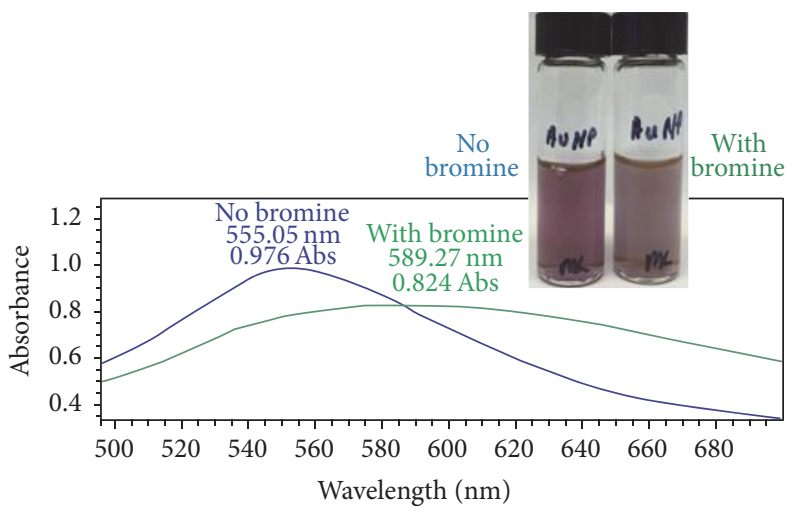

FIGURE 7: Image of the resulting gold nanoparticle solutions prepared in the absence of $\mathrm{KBr}$ (left) and in the presence of $0.075 \mathrm{mM} \mathrm{KBr}$ and their corresponding UV-Vis spectra.

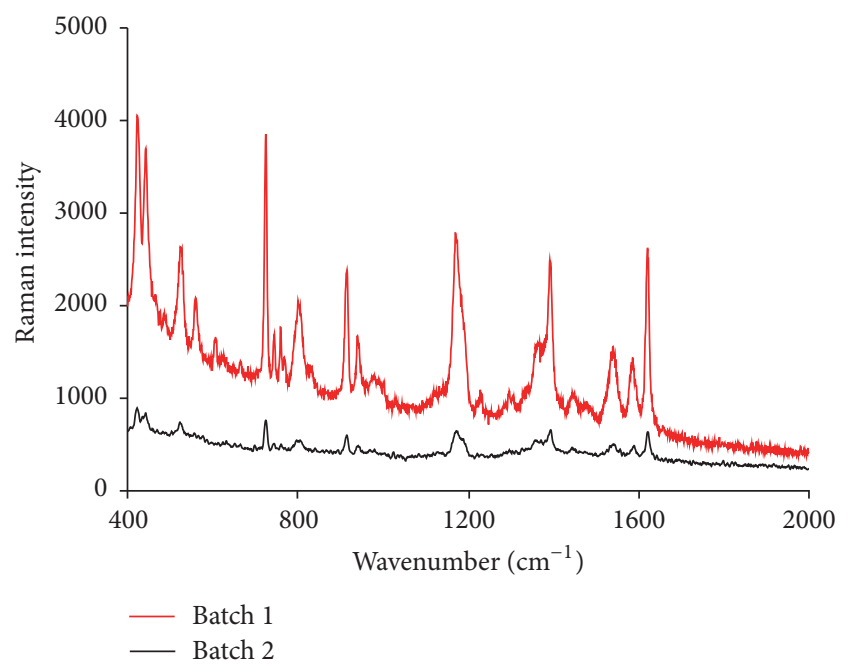

FIGURE 8: SERS spectra of crystal violet $(1 \mathrm{mM})$ from different batches of Au NPs. Batch 1: Au NPs prepared in the presence of $0.075 \mathrm{mM} \mathrm{KBr}$. Batch 2: Au NPs prepared in the absence of KBr.

\section{Competing Interests}

The authors declare that there are no competing interests regarding the publication of this paper.

\section{Acknowledgments}

This work was supported by the National Science Foundation (Awards nos. HRD-1238441 and DMR-1523617) and North Carolina Space Grant Consortium. The authors thank the Shared Materials Instrumentation Facility (SMIF) at Duke University and Dr. Marvin Wu at the Department of Mathematics and Physics at NCCU for granting them access to the scanning electron microscopes.

\section{References}

[1] J. R. Ferraro and K. Nakamoto, Introductory Raman Spectroscopy, Academic Press, Boston, Mass, USA, 2nd edition, 1994.
[2] C. V. Raman and K. S. Krishnan, "A new type of secondary radiation," Nature, vol. 121, no. 3048, pp. 501-502, 1928.

[3] T. von Foerster, "Surface-enhanced Raman effect," Physics Today, vol. 33, no. 4, pp. 18-20, 1980.

[4] A. Campion and P. Kambhampati, "Surface-enhanced Raman scattering," Chemical Society Reviews, vol. 27, no. 4, pp. 241-250, 1998.

[5] M. Fleischmann, P. J. Hendra, and A. J. McQuillan, "Raman spectra of pyridine adsorbed at a silver electrode," Chemical Physics Letters, vol. 26, no. 2, pp. 163-166, 1974.

[6] B. K. Jena, S. Ghosh, R. Bera, R. S. Dey, A. K. Das, and C. R. Raj, "Bioanalytical applications of Au nanoparticles," Recent Patents on Nanotechnology, vol. 4, no. 1, pp. 41-52, 2010.

[7] M.-C. Daniel and D. Astruc, "Gold nanoparticles: assembly, supramolecular chemistry, quantum-size-related properties, and applications toward biology, catalysis, and nanotechnology," Chemical Reviews, vol. 104, no. 1, pp. 293-346, 2004.

[8] K. Saha, S. S. Agasti, C. Kim, C. X. Li, and X. V. M. Rotello, "Gold nanoparticles in chemical and biological sensing," Chemical Reviews, vol. 112, no. 5, pp. 2739-2779, 2012.

[9] D. A. Giljohann, D. S. Seferos, W. L. Daniel, M. D. Massich, P. C. Patel, and C. A. Mirkin, "Gold nanoparticles for biology and medicine," Angewandte Chemie-International Edition, vol. 49, no. 19, pp. 3280-3294, 2010.

[10] Y. K. Shrestha and F. Yan, "Determination of critical micelle concentration of cationic surfactants by surface-enhanced Raman scattering," RSC Advances, vol. 4, no. 70, pp. 3727437277, 2014.

[11] B. K. Jena and C. R. Raj, "Seedless, surfactantless room temperature synthesis of single crystalline fluorescent gold nanoflowers with pronounced SERS and electrocatalytic activity," Chemistry of Materials, vol. 20, no. 11, pp. 3546-3548, 2008.

[12] P. K. Jain, K. S. Lee, I. H. El-Sayed, and M. A. El-Sayed, "Calculated absorption and scattering properties of gold nanoparticles of different size, shape, and composition: applications in biological imaging and biomedicine," Journal of Physical Chemistry B, vol. 110, no. 14, pp. 7238-7248, 2006.

[13] S. Jain, D. G. Hirst, and J. M. O’Sullivan, “Gold nanoparticles as novel agents for cancer therapy," British Journal of Radiology, vol. 85, no. 1010, pp. 101-113, 2012.

[14] J. Z. Zhu, Y. Shen, A. Xie, L. Qiu, Q. Zhang, and S. Zhang, "Photoinduced synthesis of anisotropic gold nanoparticles in roomtemperature ionic liquid," The Journal of Physical Chemistry C, vol. 111, no. 21, pp. 7629-7633, 2007. 
[15] H. E. Cramer, L. Giri, M. H. Griep, and S. P. Karna, "Shapecontrolled gold nanoparticle synthesis," Tech. Rep. ARL-TR6662, U.S. Army Research Laboratory, Aberdeen, Md, USA, 2013.

[16] B. K. Jena and C. R. Raj, "Shape-controlled synthesis of gold nanoprism and nanoperiwinkles with pronounced electrocatalytic activity," Journal of Physical Chemistry C, vol. 111, no. 42, pp. 15146-15153, 2007.

[17] B. Xiong, J. Cheng, Y. Qiao, R. Zhou, Y. He, and E. S. Yeung, "Separation of nanorods by density gradient centrifugation," Journal of Chromatography A, vol. 1218, no. 25, pp. 3823-3829, 2011.

[18] P. J. Straney, C. M. Andolina, and J. E. Millstone, "Seedless initiation as an efficient, sustainable route to anisotropic gold nanoparticles," Langmuir, vol. 29, no. 13, pp. 4396-4403, 2013.

[19] J. Clark, "Redox reactions involving halide ions and sulphuric acid," 2002, http://www.chemguide.co.uk/inorganic/group7/ halideions.html.

[20] O. M. Magnussen, "Ordered anion adlayers on metal electrode surfaces," Chemical Reviews, vol. 102, no. 3, pp. 679-725, 2002.

[21] S. H. Lee, B. K. Salunke, and B. S. Kim, "Sucrose density gradient centrifugation separation of gold and silver nanoparticles synthesized using Magnolia kobus plant leaf extracts," Biotechnology and Bioprocess Engineering, vol. 19, no. 1, pp. 169-174, 2014. 

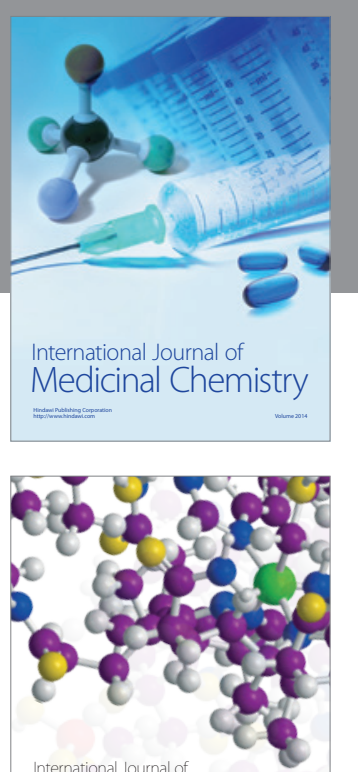

Carbohydrate Chemistry

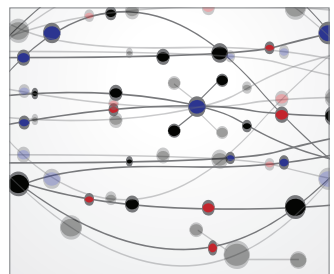

The Scientific World Journal
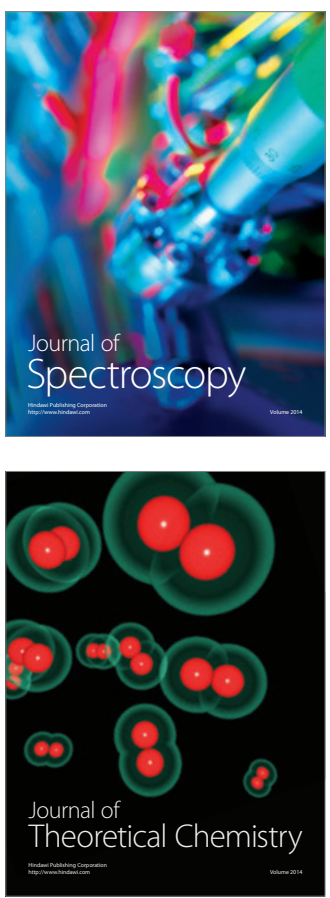
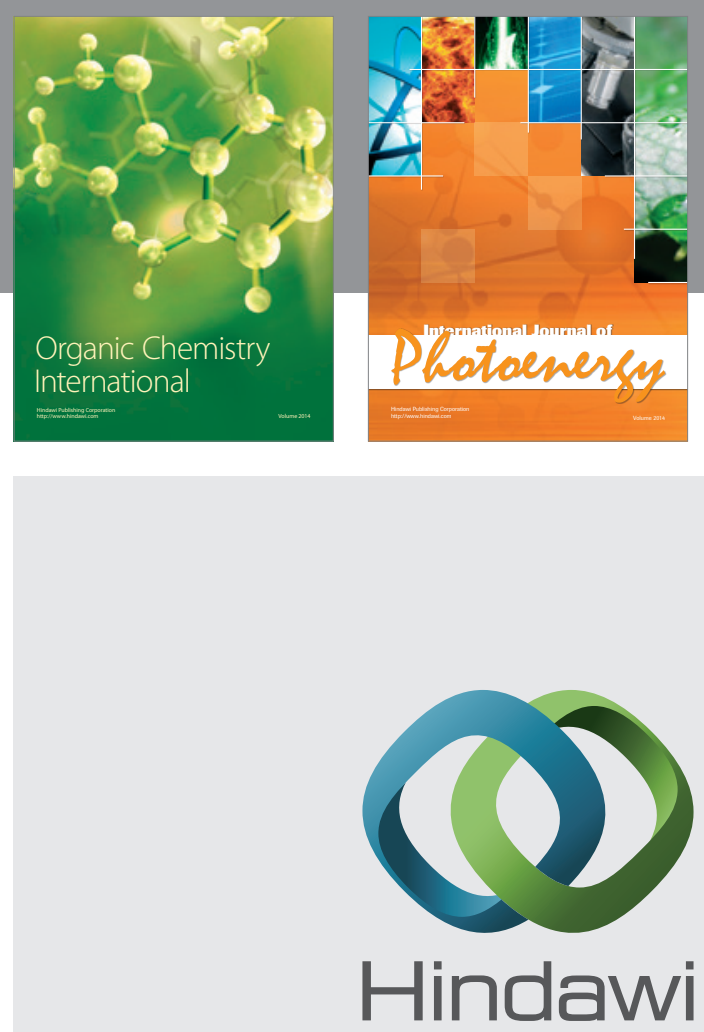

Submit your manuscripts at

http://www.hindawi.com

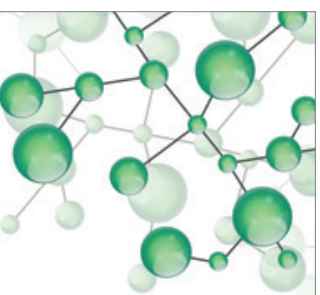

International Journal of

Inorganic Chemistry

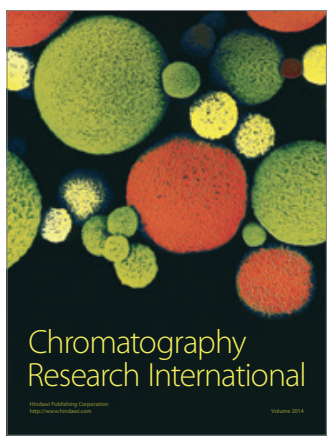

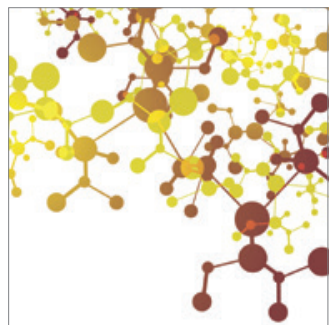

Applied Chemistry
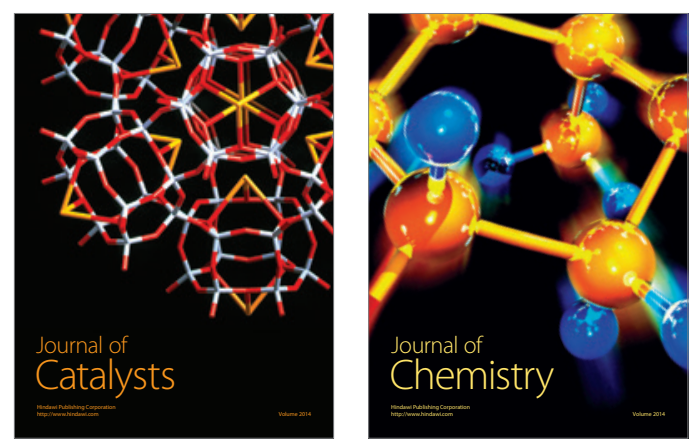
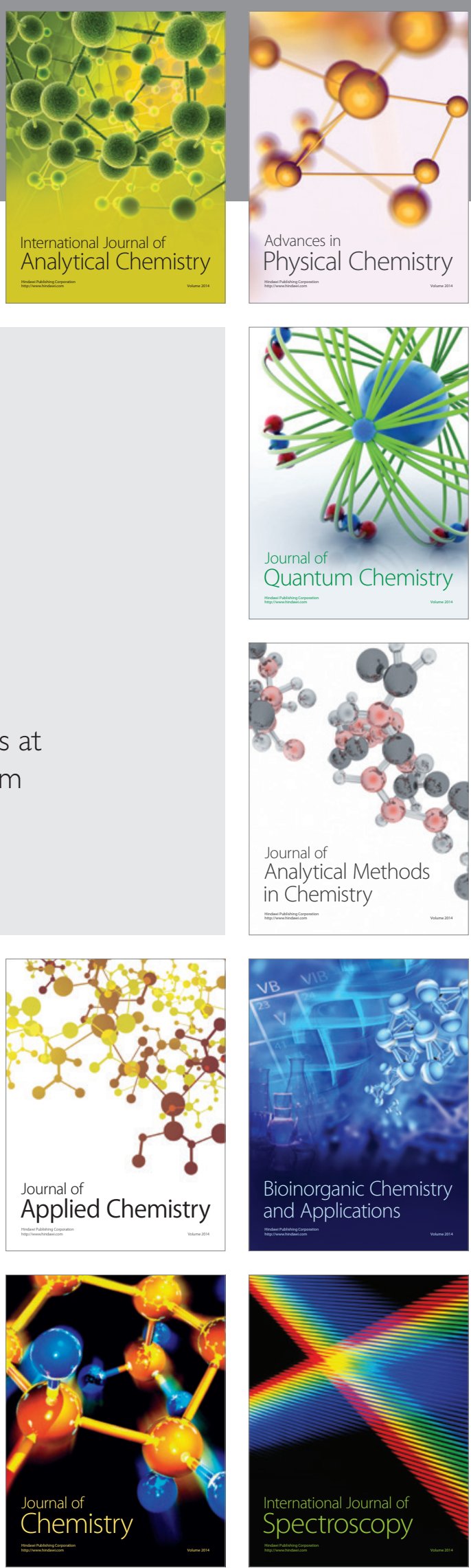